NBSIR 83-2743

\title{
The Preservation of the Constitution of Puerto Rico
}

U.S. DEPARTMENT OF COMMERCE National Bureau of Standards

Washington, DC 20234

June 1983

Final Report

$Q Q$ ared for

100

.456 tional Archives and Records Service ishington, DC

$83-2743$

1983

C. 2 

NBSIR 83-2743

THE PRESERVATION OF THE CONSTITUTION OF PUERTO RICO

Elio Passaglia, Daniel Brown, Brian Dickens

U.S. DEPARTMENT OF COMMERCE

National Bureau of Standards

Washington, DC 20234

June 1983

Final Report

Prepared for

National Archives and Records Service

Washington, DC

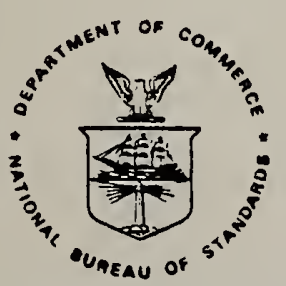

U.S. DEPARTMENT OF COMMERCE, Malcoim Baldrige, Secretary NATIONAL BUREAU OF STANDARDS, Ernest Ambler, Director 


\section{ABSTRACT}

A general design for a display enclosure for the Constitution of Puerto Rico, and designs and methods of construction of hermetically sealed cases to contain the constitution documents are presented. 



\section{THE PRESERVATION OF THE CONSTITUTION OF PUERTO RICO}

FINAL REPORT

\section{Introduction}

This is the final report on the project, "The Preservation of the Constitution of Puerto Rico". The purpose of this project was to arrive at a design for the cases to hold the documents on which are printed the Constitution of Puerto Rico, and the enclosure in which they were to be placed. The design of the cases was to be tested by constructing and testing two prototype cases. Both the enclosure and the cases serve primarily to protect the documents from vandalism and from degradation by ultraviolet light and oxygen. The report will first consider the general requirements, then discuss the enclosure, and finally the design and construction of the cases.

\section{General Requirements*}

The Constitution of Puerto Rico is printed on 29 sheets of parchment approximately $24.8 \times 17.9 \mathrm{~cm}(93 / 4 \times 71 / 16 \mathrm{in.})$. The thickness varies from $0.15 \mathrm{~mm}(0.006 \mathrm{in.})$ to $0.25 \mathrm{~mm}(0.010 \mathrm{in.})$. The text on them occupies a space $18.4 \times 11.7 \mathrm{~cm}(7-1 / 4 \times 45 / 8$ in. $)$. These are to be placed on display on a circular urn (pedestal) measuring $139.7 \mathrm{~cm}$ (55 in.) in diameter and $92.4 \mathrm{~cm}(36-3 / 8 \mathrm{in.}$ ) high. The pedestal contains a recess $10.5 \mathrm{~cm}(4-1 / 8$ in.) deep and $119.4 \mathrm{~cm}$ (47 in.) in diameter. The site is relatively open to the exterior.

The documents have been on display on this site under a glass cap which has the shape of a portion of a sphere. Condensation of moisture has occurred on the inside of this cap leading to etching of the glass. The documents themselves appear to be in excellent condition. The documents rested on a flag of Puerto Rico $155 \times 91.4 \mathrm{~cm}(36 \times 61$ in. $)$ in size. This flag is to be contained in the final display as well.

*The material in the first two paragraphs was provided to NBS by Dr. C. Shahani, then of NARS, now with the Library of Congress. 
The general requirements arrived at with Dr. Shahani on the final display are as follows:

(a) It be esthetically pleasing and dignified.

(b) The documents be protected from degradation. This means protecting then from harmful ultra-violet light and oxygen while maintaining sufficient water content in the parchment.

(c) The documents be protected from vandalism.

(d) No condensation occur on whatever enclosure contains the documents.

It is to be noted that the overall design has to combine esthetic and technical judgments. The esthetic judgments cannot be made by NBS. However, the designs which are to be described do appear to be esthetically pleasing, but the final design may be changed by esthetic considerations while balancing the technical ones.

Considering these various factors, the conceptual design that was considered is that the documents would be placed in cases similar to the cases that presently contain the U.S. Constitution and Declaration of Independence. These in turn would be placed in an outer case (called the enclosure here). Both these can serve the function of protecting the documents. These will now be discussed.

3. The Enclosure and Protection from U1tra Violet Degradation

3.1 General Design

It should be noted at the outset that it is possible to display the documents in their cases without an enclosure. In many ways this simplifies the design and construction of the display. This would, however, leave the document cases accessibl to the public and possible damage, so the design of an enclosure was pursued.

The general design of the enclosure cannot be discussed adequately without a few words about the size of the cases needed to hold the documents. This will be discussed more thoroughly later. We were originally informed that the light incident on the urn comes principally from east and west, and that it would therefore be preferable to contain the documents in two cases facing north and south to 
minimize exposure to ultra-violet radiation. The minimum size case under these conditions is $33 \times 39 \mathrm{in}$., with one case containing fifteen docuinents and the other fourteen*. Much of the effort was therefore expended in methods of construction of these cases. These will be called the "large cases". Subsequent measurements of the light distribution at the site showed, in fact, that there was no directionality (1). Because the large cases are heavy and difficult to handle, smaller cases were also worked on. The documents can be contained in four cases $18-3 / 8^{\prime \prime} \times 24^{\prime \prime}$, being displayed on both sides. These will be discussed more fully later, and will be called the "small cases".

While there is some flexibility in the design of the enclosure, much of this is circumscribed by the shape of the urn, the requirement that no condensation occur in it, and that it be high enough to contain the cases containing the documents. A section and plan view of a possible design for the total exhibit is shown in Figure 1. The scale is $1=15$. On the existing urn there is to be set a cylinder of polymethylmethacrylate. The cylinder is set into the $4-1 / 8$ in. recess of the urn. The figure is drawn with the $18-3 / 8 \times 24$ in. cases, which are arranged in the form of a cross, and are to be viewed from both sides. Since there are 29 documents in the Puerto Rican Constitution, one arrangement is for five of the eight case sides to contain four documents (as shown) while the other three sides contain three documents (not shown), although other arrangements are possible. The height of the center of the documents is $4 \mathrm{ft}$. $6 \mathrm{in}$. in this drawing. Other heights are, of course, possible.

If the $33 \times 39$ in. cases are chosen, only one or two cases would be necessary, one containing fifteen documents, and the other fourteen. With this arrangement, viewing would be from two sides only. A drawing of this has not been made.

No details of the supporting structure are shown. The reason for this is that esthetic considerations will play an important part in its design, and once the esthetic requirements are established, design and construction is expected to be straightforward. 


\subsection{Condensation Prevention}

As previously mentioned, it has been reported to NBS that condensation has occurred on the inside surface of the present enclosure. This presumably happened during the night when the temperature on the outside of the enclosure dropped. This in turn implies that the interior of the enclosure is somehow connected to a source of warm, moist air. No details are available to us on this point, or on the tightness of construction of the present enclosure.

Whatever the source of the present condensation, there are several ways to prevent it in whatever enclosure is constructed. They all have one aspect in common: the enclosure should be tightly constructed which in turn complicates the assembly of the enclosure, as will be discussed later. If the cylindrical enclosure shown in figure 1 is chosen, then its top and bottom should be sealed to make them air tight. One obvious way to do this is with gasketing material and screws. Simply sealing it in this manner should prevent a great deal of condensation, provided the interior is dry when sealed.

There are two other means of preventing condensation. The first, suggested by Dr. Shahani, is air conditioning. An air conditioning unit mounted under the floor of the site and blowing conditioned air into the enclosure should preclude condensation on the inside of the enclosure. However, it is possible that the air conditioning might cool the enclosure walls sufficiently that condensation might occur on the outside of the enclosure, particularly as the outside air is likely to be humid. Because of this, if air conditioning is used, it should be combined with temperature control of the air inside the enclosure.

The second means of controlling condensation on the inside of the enclosure is to keep the air dry. A dessicant is an obvious solution, but this would need period replacement, which would complicate the design of the enclosure, and might be unsightly. One other way to overcome this is to keep the enclosure under a slight overpressure of dry inert gas such as nitrogen. This could be easily accomplished by a connection through a valve through the base of the enclosure, assuming there is 
room under the base of the site. This would require periodic maintenance, and most importantly, a safety mechanism to assure that the pressure does not rise too high.

of the various alternatives, the air conditioning seems the most direct and the best established technology. The second alternative would be simply a sealed enclosure, which should alleviate a large part of the problem if moisture indeed enters the present enclosure through the bottom of the urn.

\subsection{U1 tra-Violet Protection}

Protection from ultraviolet will have to be provided for the documents. This is particularly important in that Dr. Shahani (1) informed us that the illumination level is 65 foot candles, which is quite high compared to the 10 foot candles he informed us is more normal for display purposes.

To determine the degree of protection that would be provided by three alternatives, calculations were carried out for filters of UF1, UF3 and 2208 Plexiglas*. These three materials, produced by the Rohm and Haas Corporation, provide increasing protection, but at the expense of some yellowing in color. The incident radiation used for this calculation was the mean insolation at a latitude of $38{ }^{\circ} \mathrm{N}$, and damage was calculated as in the NBS report, "Preservation of the Declaration of Independence and Constitution of the United Ștates". The ratio of the damage with these materials to that without them is as follows:

\begin{tabular}{lc} 
Material & Damage with/Dam \\
\cline { 2 - 3 } & 12 \\
UF3 & 6.8 \\
UF3 2208 & 0.2
\end{tabular}

Because of the high level of illumination it would be best to use the 2208 despite its yellow color.

The filters may be placed in several locations. The most obvious is on the case itself. For this purpose special holders could be placed on the decorative bronze *Certain commercial products were used in the construction of the prototype cases described in this report. These materials are mentioned by trade name in order to adequately describe them for purposes of design and construction of the final cases. Other materials may be suitable for some of these purposes, but we have no information on the performance of alternative materials beyond those reported here. 
borders of the cases to hold $1 / 8^{\prime \prime}$ thick sheets of the absorber. This would provide optimum protection and could easily be removed for replacement. Another and perhaps better location is on the supporting structure. Neither of these locations offers any problem for the ultimate design.

\subsection{Assembly}

The assembly of the display will be a complex procedure to be done at the site. This complexity is caused by the requirement that the enclosure be sealed, possibly attached to an air conditioner, have the cases and their support structure placed in the enclosure, and bring leads from the leak monitoring system for the cases (see later under "Case Atmosphere and Leak Monitoring") to the bridge control and sensing system. To show how this could be done for the enclosure proposed here, we list the following sequence of operations to be carried out at the site. It assumes the urn is accessible from below.

1) Place the enclosure with bottom attached but with no top into the recess of the urn. The bottom will have had holes fabricated in it for air conditioning lines if necessary, and a hole for a sixteen wire feed-through plug if the four small case arrangement is chosen.

2) Attach air conditioning lines, if appropriate.

3) Lower the supporting structure with cases placed in it into the enclosure. This will require the use of a small lift at the site and is clearly a critical operation. The reason the cases need to be in the supporting structure is that the sensing leads will have had to be assembled into a cable and attached to the connector

4) Guide the connector through its appropriate hole, and seal in place from below. Attach wires from bridge control and sensing apparatus to outside pins of connector.

5) Place gasket on top of enclosure and affix top.

Should removal of the document cases for whatever reason ever become necessary, then the procedure would have to be reversed. 


\section{The Documient Cases}

\subsection{Introduction}

The document cases contain the documents for display, and serve to protect them. The primary requirements for these cases is:

1) They be esthetically pleasing and dignified.

2) They provide for physical protection of the documents.

3) They serve to maintain the documents under an inert atmosphere.

The third of these requirements is the most difficult to satisfy since it involves placing the documents in a hermetically sealed case under the proper atmosphere. Much of the analysis carried out for the Puerto Rican documents was based on the cases that now contain the Declaration of Independence and the Constitution of the U.S. These are described fully in NBS Circular 505 (2) and will be described more fully later. The Puerto Rican situation is very similar, but has one important difference, namely the size and number of the documents to be displayed. This requires revision of the overall design of the U.S. cases, al though this revision is not critical. The critical element is the hermetic seal. These various factors will be discussed in the next three sections.

\subsection{Overall Design}

\subsubsection{Large Cases}

As previously mentioned, original considerations of the directionality of the illumination of the Puerto Rican display site indicated that it might be best to display the documents in two cases oriented north and south, since it was believed that the illumination come principally from the east and the west. Considering the size of the twenty-nine documents of the Puerto Rican Constitution $(9-3 / 4 \times 7-1 / 16$ in. $)$ the minimum size case that can contain them is $33 \times 39$ in. Final detailing for construction might alter their dimensions slightly. Such a layout is shown in Figure 2, which is drawn to a scale of 1-4.38. The documents are displayed in three rows of five each on one side, and two rows of five and one of 
four on the other (this is not shown). The case has around it a decorative bronze border. Clearly, a single case of this size would contain all the documents if they are so placed to be viewed from both sides of the case. Such a "two sided" arrangement will be described below under the small cases.

The dimensions $33 \times 39$ in. are arrived at as follows. The documents are placed with $3 / 16$ in. between their long edges and $3 / 8$ in. between their short edges. Around the edge of the documents $1-1 / 2$ in. is left for the bracket and construction (see later). This gives dimensions of $33 \times 39.06 \mathrm{in.,}$ or nominally $33 \times 39$ in. Clearly, some adjustment of these dimensions is possible for esthetic considerations. It should be pointed out, however, that with a circular enclosure as previously discussed of a wall thickness of $1 / 2$ in., two $33 \times 39$ in. cases would be approximately $12 \mathrm{in.} \mathrm{from} \mathrm{the} \mathrm{center} \mathrm{of} \mathrm{the} \mathrm{enclosure.} \mathrm{Larger} \mathrm{cases}$ would have to be placed closer to the center.

The documents would be overlaid by a mat with viewing windows cut into it that are larger than the text. This mat would be made of pure a cellulose paper to control humidity of the interior atmosphere as is done in the U.S. cases. This will be discussed later. These windows are shown as heavy lines in Figure 2. This assembly is then overlaid by a pane of glass held by a bracket. This will be discussed more fully below under small cases, as will the problem of slippage of the documents.

\subsubsection{Smal1 Cases}

As will be described more fully later, the large cases are heavy, and more difficult to construct and handle than smaller cases. For this reason, after measurements of the illumination showed that it was not directional, smaller cases were considered. The documents can be contained in four cases 18-3/8 in. $x 24$ in., with the documents being viewed from both sides of the cases. Since there are eight viewing sides, there are a number of possible arrangements of the documents, with perhaps two suggesting themselves: five sides with four documents and three sides with three, or seven sides with four documents and one side with one. 
A view of the arrangement with four documents on a side is shown in Figure 3 , at a scale of 1-2.4. The description of the layout is as above under the large cases, except that 2 in. is left around the documents. A side with only three documents is not shown.

For either the large cases or the small cases, stability of the arrangemnet has to be considered. In the U.S. cases, the relatively large U.S. documents are placed on a pure a cellulose mat and the whole overlaid with a cover glass and the arrangement held by friction. It was felt that to adopt the same scheme for the Puerto Rican documents would not lead to an esthetically pleasing arrangement. Moreover, there is the possibility that over time the documents could slip and spoil the symmetry of the arrangement. As a result, the design illustrated schematically in Figure 4 was developed. The documents are placed into milled recesses in a document support plate. This is a plate of bronze or other metal 1/16 in. thick. The recesses are slightly less deep than the thickness of the documents, which varies from 0.006 in. to $0.010 \mathrm{in}$. For the two sided cases, recesses are milled into the plate on both sides. The mat then overlays the documents as shown in the exploded view in Figure 4.

Final details of the assembly are shown in Figure 5 , which shows a section of the two sided case. The documents lie in recesses in the document support plate. They are overlain by the pure a cellulose mat. These in turn are overlain by $1 / 8$ in. thick glass cover sheets. The whole arrangement is held together by the bracket which in turn supports the $1 / 4 \mathrm{in}$. thick outer plates of glass. The whole arrangement is hermetically sealed by the lead strip which is soldered to the metal deposited on the glass. For the one-sided large case, the document support plate would rest against one of the outer glass plates, and the bracket would be suitably modified. The decorative outer bronze frame is not shown. 


\subsection{Physical Protection}

It was requested 'that physical protection of the documents, particularly against possible vandalism, be considered by NBS in the design of the document cases. At the very minimum, this would require tempered glass for at least the exterior glass of the cases. Laminated glass would be preferable, for it would provide greater protection than tempered glass, and the early directions of the case construction phase of this project were conditioned by this requirement. As will be described later, it became apparent that this requirement was too cumbersome to meet, and tempered glass was settled upon to provide the protection.

The thickness of the glass is still an option. The U.S. cases are of nominal 1/4 in. thick glass, and all the experimentation on this project was carried out with this thickness. Nominal $1 / 2$ in. thick glass would provide much greater protection. It leads, however, to cases that are qui te heavy, and perhaps not as esthetically pleasing as those with the thinner glass. Approximate calculated weights for these two thicknesses of glass are given in Table 1. It is seen from this table that the large cases with $1 / 2$ in. thick glass weigh more than two hundred pounds. Even the large cases with $1 / 4$ in. thick glass are quite heavy. The table also gives the total weights of the cases in the exhibit, which is useful for design of the enclosure.

\subsection{The Hermetic Seal}

\subsubsection{Introduction}

The hermetic seal on the document cases is the most challenging and difficult aspect of the case construction. This seal must be hermetically tight so that the protective inner atmosphere will not leak out. It must be mechanically sound so as to withstand changes in temperature and atmospheric pressure. It must be constructed of materials that will not contaminate the documents. Finally, it must be durable over many years. 
The seais on the U.S. Cases (2) are indicated schematically in Figure 5. The primary seal is formed by a strip of lead which runs around the case. This lead is bonded to the glass by soldering to a copper strip approximately $1 / 4 \mathrm{in}$. wide deposited on the exterior glass. Thus the solder joints and the copper strip on the glass provide the hermetic seal and also the structural strength needed to withstand handling and pressure changes caused by changes in the ambient atmospheric pressure and temperature. The U.S. cases have served successfully for over 30 years and this method of construction was used as a standard to guide development.

The hermetic seal in the U.S. cases was provided by Libby Owens Ford, and the final sealing operations were carried out by their technicians at NBS (2). These seals were at that time used to construct thermally insulated windows and glass doors. At the present time, thermally insulated glass doors and windows are made with organic sealants, such as thiokol rubber. The older method of construction required considerable art and skill. The company is no longer in a position to provide such joints, and could not suggest another firm that could supply them.

In addition, if laminated glass were to be used for the document cases, it was not clear that soldering could be carried out without destroying the glasslaminate bond, even if laminated glass with a metal strip around the edge were available. As a result of these considerations, the whole subject of possible hermetic seals was re-investigated.

The following possible methods of sealing were considered:

1) The method used on the U.S. cases.

2) Organic sealants.

3) Mechanical Seals. 
The present method used on the U.S. cases, or, more generally, a method based on soldering to a metallic strip deposited on the glass was, as already mentioned considered to be the standard against which others were judged. It is inherently clean, and in one instance (the U.S. case) has given cases that have remained sealed for over 30 years. While under severe service conditions corrosion could be a problem in this construction, under museum conditions, which are very benign from the corrosion standpoint, this is not considered to be a problem.

The methods involving organic sealants where discarded for three reasons. First, the organic polymeric materials out of which the sealants are made will, over long times, lose volatiles consisting of low molecular weight polymer and other components. These could have an adverse effect on the contents of the case. This loss would also serve to embrittle the sealant and their durability for times greater than thirty years cannot be guaranteed. This questionable durability is the second reason they were discarded. Finally, no obvious way of assembling such a case with the documents within them was apparent.

Methods involving mechanical seals were discarded, but much less decisively than the organic materials. In such methods, a gasketing material is compressed between the outer glass plates and a suitably designed form of the bracket that appears in Figure 5. One standard form of gasket used extensively in constructing laboratory vacuum systems is an 0-ring seal. This, of course, suffers from the same problems as the organic sealants although they are much less severe, and assembly would be routine. Other gasketing materials considered were thin copper and lead strips, but over long times these materials creep and leaks could occur. Finally, the method of compression of the gasketing material would involve some kind of frame around the rim of the outer glass plates, the frame serving to compress the gaskets with screws or some other suitable means. This would, of course, put the glass under stress, and could be esthetically undesirable. For these various reasons mechanical methods were not tried, although they could warrant a development effort. 
For these various reasons it was decided to concentrate on the lead-solder method of construction used in the U.S. cases. Considering the desire to use laminated glass, the following approaches, which developed sequentially, were taken:

a) Electrodeposit a metallic strip on the glass that would have sufficient bonding to permit soldering. If possible this would have the overwhelming advantage that it is a low temperature process that could be applied to laminated glass. As described below, this approach was unsuccessful in our attempts.

b) Coat with any of a number of formulations of platinum, platinum silver, and silver dispersed in an organic matrix. These are used in the electronics industry and are applied to glass and ceramics. They involve high temperatures and hence cannot be used with laminated glass, although the glass could conceivably be laminated after the coating if necessary. The high temperatures involved during the coating process would probably remove the temper of tempered glass. On the other hand, they are relatively simple to carry out. As will be outlined below, these proved to be quite possible.

c) Coat by flame spraying. We are informed that the original cases were made by this method. It is known to be a relatively difficult process to carry out. As will be described in detail later, there are a lärge number of variables to be controlled, and the process is considerably dependent on the skill of the operator. It cannot be used with laminated glass, but can be with tempered glass. Considerable effort was expended on this method, with not completely successful results.

These various processes will be now described in detail.

\subsubsection{Electrodeposition}

As mentioned above, the deposition of a tightly adherent electrodeposited coating on the glass, would be a simple solution to the whole problem since this is a low temperature process and could be used with laminated glass. Two principal directions were followed: 
Electrodeposition of copper onto conducting glass, i.e., glass coated with a thin layer of SnO; and electroless deposition of nickel, followed by electroplating of copper over the nickel to permit soldering. A number of experiments were carried out using each of these processes by Mr. Christian E. Johnson of the NBS Electrodeposition Group. The results can be summarized by saying that coatings can be applied quite readily by either of them. They are not, however, tightly adherent. When soldering is attempted, the coating separates from the glass. Since there was no indication that this method could be made to work, even with considerable development effort, it was discarded.

\subsubsection{Coatings of Platinum, Platinum-Silver Alloys, and Silver}

As mentioned above, there are a number of commercial preparations*used to deposit metallic coating on glass, quartz, or various ceramics. They are used primarily in the electronics industry. The metals used are platinum, platinum-silver, and silver. They generally consist of organic compounds of the metal or a suspension of metal powder in an organic carrier. They are applied to the substrates by brushing or silk screening, then fired at temperatures from about $550{ }^{\circ} \mathrm{C}$ to greater than $600{ }^{\circ} \mathrm{C}$. Transfer tapes in which silver is incorporated into a special tape are also available.

A large number of experiments were carried out with five of these materials:

1) Platinum preparation 05.

2) Platinum-silver preparation 130A. Both of these are products of the Hanovia Division of Engelhard Industries.

3) Silver Transfer tapes $\mathrm{H}-75$.

4) Silver Transfer tapes H-79. Both of these are produced by the Vitta Corporation of Wilton, CT.

5) Silver suspension 7713 produced by the $D$ uPont Corporation.

The experiments consisted of placing specimens of glass in a furnace, firing at various temperatures in cycles close to those recommended by the producer, and then subjecting the coating to a preliminary evaluation. This consisted

* See footnote on page 5 . 
of testing the coating for tightness by attempting to scrape it off the glass with a razor blade, and seeing if the coating could be tinned with solder. (Soldering is not a routine operation. Special solders need to be used. This will be described later). In promising cases a lead strip was soldered to the tinned coating to simulate the final case construction to assess the mechanical integrity of the result. In the most promising case, small cases approximately eight inches square were prepared. These were assembled primarily to test methods of construction and were not subjected to any further tests.

Various surface preparations - sand blasting, hydrofluoric acid etching, and cleaning with trichloroethylene, acetone and alcohol-were tried. Adherence appeared not to be strongly dependent on surface preparation, although the surface must be clean.

The results can be summarized as follows. All these preparations can produce adherent, solderable coatings. However, the platinum and platinum-silver preparations required temperatures in excess of $560{ }^{\circ} \mathrm{C}$ in our tests. The silver preparations produced adherent coatings at lower temperatures: $550{ }^{\circ} \mathrm{C}$ for the transfer tape, and $538^{\circ} \mathrm{C}$ for the silver paint 7713.

The temperature required to produce the coating is an important consideration. All these temperatures are, of course, too high to use with laminated glass. The lamination could conceivably be applied after the coating process, but this procedure, which would have required sending out the glass for lamination after the coating, was considered to be too cumbersome for this project. Moreover, at these temperatures the glass begins to soften. For this reason, large cases could not be made in the size oven available at NBS since the glass had to be set-up on edge, and noticeable slumping occurred. However, it was thought possible that the temper of tempered glass might be preserved at the temperatures of the lowest firing materials. Indeed, several panes were prepared with the silver paint material at $538{ }^{\circ} \mathrm{C}$, and while some retained temper others did not. 
With these results in hand, and knowing that adherent coatings could be produced, arrangements were made with PPG Industries in Cockeysville, MD to temper the glass after the coating was applied but before it was fired. The reasoning behind this was that during the tempering operation the glass is heated quickly to $620^{\circ} \mathrm{C}\left(1150{ }^{\circ} \mathrm{F}\right)$ and then quenched. It was felt that adherent coatings might be produced in the tempering process itself.

On December 7, 1982, arrangements were made to carry this out at PPG. Four pieces $33 \times 40 \mathrm{in}$. and four $18-3 / 8 \times 24 \mathrm{in}$. were prepared. The glass was cut at PPG. The surfaces were cleaned with trichloroethylene, acetone, and alcohol in that order. The plan was to use both the silver paste 7713 and the transfer tape \#79 to test the process. Those panes that were to have the paint applied were laid out with masking tape leaving a 1/2 in. border along the edge. The paint was applied with a camel's hair brush. For those with the transfer tape, this was simply applied along the edge. A bare edge of $1 / 2$ in. was left on each pane to permit hanging in the tempering furnace. For the large panes this was a long edge; for the small ones a short edge.

The original plan was to make two large panes with the paint and two with the tape, and similarly for the small panes. However, the application of the transfer tape is very difficult. The tape is very fragile and it was not possible to apply it on the large panes without breaking it. Hence the four large panes were prepared with the silver paint. Two of the small panes were prepared with paint, and two with transfer tape.

The results are given in Table 2, where we have also 1 isted the results of experiments of March 22, 1983 which will be described shortly. The transfer tape did not work at all. It flaked off along the whole edge, and what remained could be easily removed. On the other hand, all the silver paint specimens gave good, adherent coatings. The obverse side of the deposited layer was a deep, rich brown. This same coloration was observed on similar specimens prepared at high temperatures in the laboratory. Whether this is a residue of the organic matrix, or a result 
of the reaction between silver oxide and glass is not known at this time. It is reported (3) that the reaction between silver and glass can produce a yellow coloration. Such yellow color was observed on thin portions of the coating that were inevitably produced at various places on the glass because of the handling of the wet paint. The coatings produced were very tight, and could not be scraped off even under hard scraping. The thickness is 0.0005 in. They were deemed sufficiently promising to assemble into a case. This was done with two of the large panes.

Handling of the panes with wet paint along the edges was very difficult. To suspend them in the tempering furnace they must be picked up and placed into grips, which then travel along a track into the furnace. Doing this without smearing of the wet coating is almost impossible. As a result, more small panes were prepared in a slightly different manner. For these, a relatively thick coating was applied at NBS, air dried for 24 hours at room temperature, and then furnace dried for ten minutes at $204^{\circ} \mathrm{C}$. This produced a dry coating. These were then taken to PPG on March 22, 1983 for tempering, and handling was much easier. The results were the same as in the previous experiments except that the coating thickness was $0.001 \mathrm{in}$. Since a great deal of the organic vehicle was removed during this operation and the same brown coloration was observed at the coating-glass interface, the hypothesis that this color may be due to a glass-silver oxide reaction is reinforced. Two of these small panes were also assembled into cases.

\subsection{Flame Spraying}

As al ready discussed in the introduction, flame spraying is another way of applying metallic coatings to glass. It has the great advantage that it can be done on tempered glass, and this is probably the way the U.S. cases were prepared.

To proceed along this direction, discussions were held with a technical representative of the Metco Corp. of Westbury, Long Island. After reviewing the various means of flame spraying copper onto glass, he recommended an experimental product produced by Metco specifically for-this purpose. It is a mixture of $75 \%$ 
high purity copper powder and $25 \%$ glass frit. The Metco designation is XP1159. The particle size is $-140+325$ mesh. The representative offered to give a demonstration of the process. Such a demonstration was carried out on December 18, 1982.

The demonstration was only marginally successful. Three $18 \times 24 \mathrm{in}$. panes were sprayed, with no single pane having a completely adherent coating. However, some portions appeared to be quite adherent, and the matter was pursued for reasons that follow.

There are a large number of critical parameters in the flame spray process. From our experience the most important appear to be:

1) Surface temperature

2) Surface cleanliness

3) Distance from the work to the flame spray gun

4) Speed of travel of the flame spray gun

In addition to these there are five spray gun parameters: Flow control valve setting, oxygen and fuel (hydrogen) pressure, and oxygen and fuel flow rates. Only the spray gun parameters were controlled during the demonstration. Consequently, it was decided to carry out experiments under controlled conditions.

One of the most critical factors is the surface temperature. To control this, a special hot plate consisting of a $1 / 2$ in. thick aluminum sheet with a total of 2000 watts of strip heaters along its edges was constructed. Surface temperature was measured by a calibrated fine, $0.010 \mathrm{in.} \mathrm{chromel-alumel} \mathrm{thermocoupl}$ Temperature accuracy is estimated at $\pm 5{ }^{\circ} \mathrm{F}$.

On March 17, 1983, six $18 \times 24$ in. panes of tempered glass were sprayed. The parameters were as follows: 1) Surface temperature: $107-113^{\circ} \mathrm{C}$. The manufacturer recommends 93-121. 2) Surface cleanliness: Wash with detergent. Scrub with magnesium oxide. Rinse thoroughly in distilled water, and assure that water flows off without droplets. Use immediately. 3) Gun distance. This was not accurately controlled on panes 1 and 2. It was controlled at 9 in. for 
panes $3,4,5,6.4)$ Gun travel speed. This was controlled at about $1 \mathrm{ft} / \mathrm{sec}$. on panes $3,4,5,6$.

In addition to the above, a special mask was constructed. It was a $1 / 8 \mathrm{in}$. thick steel plate $23 \times 171 / 2$ in. with handles so that it could be moved while hot. It was put into place in front of the pane, leaving a $1 / 2 \mathrm{in}$. border along one of the $24 \mathrm{in}$. edges of the plate, and along the two $18 \mathrm{in}$. edges. The $24 \mathrm{in}$. edge was sprayed, and half of each of the $18 \mathrm{in}$. edges. The mask was then removed, the pane rotated $180^{\circ}$, the mask replaced and spraying finished. Before using, the mask was also scrupulously cleaned. The procedure adapted was as follows.

1) Wash the pane and let drain dry.

2) Place on the hot plate and set the mask.

3) Bring up to temperature as measured by the thermocouple. This took 15-20 minutes.

4) Spray.

5.) Remove mask, rotate pane, replace mask, measure temperature again, finish spraying.

6) Let cool to about $66^{\circ} \mathrm{C}$ and remove.

At the end of this time, the glass-coating interface was inspected. The results were as follows:

Pane 1: The glass-coating interface looked reasonably sound, but in a few places the contact appeared deficient. However, the coating appeared tight.

Pane 2: This pane was washed at the same time as pane 1 . It stood in the shop for one hour before being sprayed, covered by clean paper towels. The coating was not sound, and peeled off easily in several locations. It wâs hypothesized that this was due to organic material picked up from the air. It is known that this kind of pickup can occur and make the silvering of mirrors impossible. 
Panes $3,4,5$, and 6: For these, the gun to surface distance and the velocity were controlled as given above. In addition, each was cleaned immediately before being sprayed. Each of these gave a coating that appeared sound, and were carried further. Panes $1,3,4$ and 5 were tinned. Panes 4 and 5 were assembled into a case. The result are sumnarized in Table 3. While two of the panes were carried all the way to the assembly of a case, the case leaked seriously. While this will be described more fully in the section on assembly of cases, visual inspection indicated that trouble occurred during the tinning and soldering operations The solder appeared to come through the coating, possibly along the glass fritcopper interface. For this reason, one final experiment was carried out: spraying with pure copper powder.

Spraying with pure copper is similar to spraying with the copper-glass powder, except that two converging streams of air are injected into the flame. This adds another parameter to be controlled, namely the air pressure. The manufacturer recommends a range of 15-70 PSIG, and after consultation with Metco representatives, this was set at 60 PSIG. Three panes were sprayed by this technique, with results shown in Table 1. Everything else was the same as in the copper-glass spraying except that the glass temperature was $149-166{ }^{\circ} \mathrm{C}$ and the gun travel speed was about $0.5 \mathrm{ft} / \mathrm{sec}$. These conditions were chosen in consultation with Metco. Nine passes were made.

The coatings produced appeared better than with the copper-glass mixtures. Their thickness was about $0.003 \mathrm{in.}$, and they could not be lifted. Upon tinning, however, one corner on the first pane lifted, although there was no apparent transmission of solder through the coating. The others tinned well, but upon assembly into a case, leakage occurred at the corners, and there was small but obvious lifting of the coating.

\subsection{Case Assemb7y}

Having glass panes with a metal coating along the edges, these must then be assembled into cases by soldering. For this purpose the following procedure was followed: 
1) apply a thin layer of solder to the coating, i.e., tin the coating.

2) Fabricate lead strips which are to be soldered to the coating as shown in Fig. 5, and tin these strips as well. Weld the strip into a rectangle, with $1 / 4$ in. holes in opposite corners to affix copper tubes for leak testing.

3) Fabricate bracket also shown in cross section in Figure 4. This fits just inside the lead strips. It has $1 / 4 \mathrm{in}$. holes every six inches to facilitate passage of the filling and/or leak testing gas into the inside of the case. For the purpose of testing the construction, it was not felt necessary to have the document support plates, the inner glass, or the documents and mat in the case. These were not used for the prototype cases. In addition, commercially available al uminum extrusion was used for the bracket rather than the bronze or brass to be used in the final case, which requires fabrication.

4) Solder the lead strip onto one pane and affix the tubes for leak testing. Place the bracket inside the half formed case, place the other pane on it, turn over and solder to the lead strip.

5) Affix valves to the copper tube and flush with helium. Pressurize to a low pressure (approx. $0.5 \mathrm{in} \mathrm{Hg}$ ) of helium and test thoroughly with a helium leak detector.

There are two critical elements in this procedure: tinning and the associated choice of solder, and the final assembly soldering. These were carried out by Mr. Bruce Beuchert, master welder in the NBS shops.

The solder recommended for the silver coatings has a composition of $62 \% \mathrm{Sn}$, $36 \% \mathrm{~Pb}$ and $2 \% \mathrm{Ag}$. This is obtainable in a paste form in which it is mixed as powder with flux, or in the form of flux cored wire. Various flux grades are available from very active to mildly active. The latter was preferred because of its less aggressive character. Several other solders and fluxes were tried, but best results were obtained with this one even on the copper coatings and hence 
it was this one used. It has the advantage that it melts at the relatively low temperature of $179{ }^{\circ} \mathrm{C}$ as compared to $183^{\circ} \mathrm{C}$ for $63-37$ eutectic solder, 183-193 ${ }^{\circ} \mathrm{C}$ for $60-40$ solder, and $183-216{ }^{\circ} \mathrm{C}$ for $50-50$ solder.

Tinning was carried out with both solder paste and wire. When paste was used, a bead of the paste was laid down along the coating strip, and a 500 watt iron operated at about seventy volts used for the tinning. When wire was used, the same iron was used, and passed down the coating following the iron. Motion was as rapid as possible to avoid overheating. Generally 1-2 in. per second was obtainable. A final pass in the opposite direction was made. Excess flux was removed with trichlorethylene.

It was found advantageous to heat the substrate gently. For this purpose, the $18 \times 24$ in. panes were heated to $66^{\circ} \mathrm{C}$ on the special hot plate. This could not be done for the large panes.

For final assembly, a bead of solder was laid at the lead strip-tinned coating joint. In this case a 100 watt round faced iron was used. Heat was applied preferentially to the lead.

Four cases were taken to final assembly: One large silver case, one small silver case, and two small copper cases. The results are shown in Table 5. The two cases with the silver coating produced tight cases. They showed no leaks with the helium leak detector and were left for about three days under pressure with a sensitive gauge calibrated in inches of water and sensitive to \pm 0.1 in water $( \pm 0.007$ in $\mathrm{Hg})$. This showed no change other than fluctuation (both up and down) with room temperature. These were therefore sent to environmental testing.

Two copper cases $18 \times 24 \mathrm{in}$. in size were also taken to final assembly. Critical inspection of the coating after tinning indicated that the coating was still tight, although, as previously mentioned, there was some indication that the solder had come through the coating on the copper-glass preparation. There was little if any sign of this on the pure copper preparation. After final 
assembly, both coatings showed obvious separation from the glass. This was far more obvious in the copper-glass preparation than in the pure copper one. Indeed, the former could be stripped from the glass with a knife. This was done to recover the bracket for construction of the final case. The final case is on hand for further study if appropriate. This experience attests to the critical nature of the soldering operation.

Low magnification examination indicated that in both cases the melting of the copper particles was not complete, which in turn indicates that either the substrate was not hot enough or the copper particles were not when they hit the surface. This could lead to incomplete fusion of the copper particles in the coating and hence to subsequent penetration of solder along the interparticle boundaries. It was not possible to explore these matters with the time and funds available. Flame spraying may be made to work, but the critical conditions for it were not attained in this investigation.

\section{Environmental Testing}

The museum conditions under. which hermetically sealed display cases are used and are very mild and benign. Nevertheless, changes in temperature and atmospheric pressure will cause stresses and deflections in the cases, and it was felt necessary and prudent to test the ability of the cases to withstand them. In addition, while it is notoriously difficult to extrapolate from short term tests to long term durability, choice of test conditions more severe than those encountered in service can give some qualitative assurance on the durability of the cases. For this reason the cases were subjected to environmental testing. We were assisted in this by personnel at the Harry Diamond Laboratories who carry out such testing on U.S. military equipment.

Conditions in Puerto Rico are quite mild. The Encyclopedia Brittanica gives record high and low temperature of $94^{\circ} \mathrm{F}$ and $62{ }^{\circ} \mathrm{F}$ in San Juan. Monthly mean temperatures are $80^{\circ} \mathrm{F}$ in summer and $75^{\circ} \mathrm{F}$ in winter, with a daily change of only $7^{\circ} \mathrm{F}$. U. S. Weather Bureau records indicate that the record temperatures 
for all of Puerto Rico are $103^{\circ} \mathrm{F}$ and $40^{\circ} \mathrm{F}$. In addition, inspection of daily atmospheric pressure ranges for 1979 and 1980 indicate a high pressure of 30.05 in. $\mathrm{Hg}$ obtained on several dates, and a low of 29.71 attained on August 30, 1979. The pressure is expected to be considerably lower during hurricanes, which, according to the U.S. Weather Bureau reports occur only infrequently in Puerto Rico. The last hurricane to hit Puerto Rico was hurricane Betsy on August 12, 1956 . Hurricanes are important because the low atmospheric pressure associated with them causes stresse on the cases. To provide a considerable margin of safety temperature limits of $50^{\circ} \mathrm{F}\left(10^{\circ} \mathrm{C}\right)$ and $130^{\circ} \mathrm{F}\left(54^{\circ} \mathrm{C}\right)$ were used in the testing. This allows for quite wide changes in atmospheric pressure, such as occur in tropical storms, as will be shown shortly. The cycle chosen is shown in Figure 6 . The cases were subjected to a four hour temperature cycle, or six per day. There is a dwell time of one hour at both the highest and lowest temperatures, with one hour each for the temperature increasing and decreasing parts of the cycle.

The equivalent conditions in service corresponding to the test conditions may be calculated in the following way. The deflection of the center of a uniformly loaded rectangular plate with rigidly fixed edges is given by (5)

$$
y=k w r^{4} / E t^{3}
$$

where $y$ is the deflection, $w$ is the load in force per unit area, $k$ is a constant depending on the length to width ratio of the plate, $r$ is the width of the plate, $t$ its thickness and $E$ the Young's modulus of the plate material. Now, if the document case is filled at a pressure $P_{0}$ and temperature $T_{0}$, then changes in the ambient pressure and temperature will produce differences between the internal pressure in the case and the ambient pressure, and hence produce deflection in the case. That is, we may write

$$
y=c w=c\left(P_{i}-P_{a}\right)
$$

where $c$ is a constant, $P_{i}$ is the internal pressure in the case and $P_{a}$ the ambient pressure. As the outer glass of the case deflects, however, the 
internal pressure is decreased, and this is particularly true for the full cases since the amount of gas space in them is small. If the case is filled at a pressure $P_{0}$ and temperature $T_{0}$, and if the form of the deflected outer glass is approximated as a pyramid, then a short calculation leads to the following relationship between the deflection and the ambient temperature and pressure

$$
y=\frac{-\left(3 d+c p_{a}\right)+\sqrt{\left(3 d+c P_{a}\right)^{2}-12 c d\left(P_{a}-P_{0} T_{a} / T_{0}\right)}}{2}
$$

where $P_{a}$ is the ambient pressure, $T_{a}$ the absolute ambient temperature, and $d$ the thickness of the bracket arm, which largely determines the volume of gas in the filled case. Entering the constants for the large and small cases we obtain

and

$$
y=\frac{-\left(0.375+.171 P_{a}\right)+\sqrt{\left(0.375+0.171 P_{a}\right)^{2}-0.257\left(P_{a}-14.6\right) T_{a} / T_{0}}}{2}
$$

$$
y=\frac{\left.-\left(0.375+0.018 P_{a}\right)+\sqrt{\left(0.375+0.018 P_{a}\right)^{2}-0.341\left(P_{a}-14.6\right) T_{a} / T_{0}}\right)}{2}
$$

where $P_{0}$ has been taken as standard atmospheric pressure (14.6 PSI). With this analysis it is possible to calculate the correspondence between the test temperatures of $50^{\circ} \mathrm{F}\left(10^{\circ} \mathrm{C}\right)$ and $130^{\circ} \mathrm{F}\left(54^{\circ} \mathrm{C}\right)$ at atmospheric conditions and the conditions at the temperature extremes in Puerto Rico of $62^{\circ} \mathrm{F}\left(17^{\circ} \mathrm{C}\right)$ and $94^{\circ} \mathrm{F}$ $\left(34^{\circ} \mathrm{C}\right.$ ) by the conditions that the deflection (and hence the stress) be the same. The results are shown in Table 6 . This shows that the selected test conditions correspond to the temperature extremes of San Juan plus an added pressure fluctuation of about five inches of mercury. These would be expected to encompass the extreme conditions found in service except possibly under the most severe hurricane conditions. 


\subsection{Testing Procedure and Results}

Testing was carried out for three sets of conditions:

a) Conditions as described above. This was carried out for two fourteen day periods with six cycles a day. Leak testing was carried out between the two periods.

b) Extremely severe hurricane conditions. The conditions chosen were $70^{\circ} \mathrm{F}$ $\left(2{ }^{\circ} \mathrm{C}\right.$ ) and $25 \mathrm{in} . \mathrm{Hg}$. These are the conditions expected in the eye of a once in a hundred year hurricane (6). Three cycles of ten minutes each to these conditions were used.

c) Air Transport. A cabin pressure corresponding to $12,500 \mathrm{ft}$. altitude and a temperature of $70^{\circ} \mathrm{F}\left(21^{\circ} \mathrm{C}\right)$ were assumed to provide a safety factor over a cabin altitude of 10,000 ft. One cycle of one half hour was used.

The cases that were tested were one large case and one small case, both constructed with the silver coating. They are listed in Table 5. Allowance had to be made for the fact that the prototype cases were empty. They did not contain the documents, mat, and interior glass. The test conditions for these empty cases that correspond to the full ones, which can be calculated easily from Eq. 3, are different for the large and small cases. As a result the large case experienced a full two weeks of severe hurricane testing. The results can be summarized as follo

1) The large case passed all the tests satisfactorily.

2) After the four weeks of testing, the small case developed a leak at the joint where the copper tube entered the case. Upon close inspection, this joint was deficient, and was repaired. This is not considered a serious problem. After hurricane testing, the case developed a small pinhole at a spot on the solder-silver coating joint where the silver coating was not as well applied as in the rest of the case, showing brush marks. This was repaired. However, during the air transport testing, this area of the case developed a more serious leak. Careful inspection of this area and the rest of the joint in the small case indicated: 
a) The area where the leak occurred was an area where the silver coating was mis-applied as noted above.

b) The solder fillet on the small case was much smaller than in the large case. This was done purposely to minimize heating of the silver coating, but it is clear that the stress on the coating with the small fillet was sufficiently high under the severe conditions of air transport to cause some de-bonding of the glass-silver joint where this joint was not perfectly made.

From the above the following conclusions can be drawn:

1) Hermetically sealed cases that will withstand the most severe anticipated service conditions can be constructed by this process.

2) While it is anticipated that the flaws that led to failure in the small case during transport testing would not occur in final construction, success cannot be guaranteed.

\section{Internal Atmosphere and Leak Detection}

Under the terms of this project, the NARS has responsibility for the atmosphere within the case. Discussions (1) indicated that the humidified helium atmosphere presently used for the U.S. cases was the atmosphere of choice. This means that the humidity should be stabilized for changes in temperature by sheets of $\alpha$ cellulose as was done in the U.S. cases. This is the reason that $\alpha$ cellulose was chosen for the material for the mat. Calculations show that the humidity is stabilized by mats of about 0.05 in. thickness. Such sheets of $\alpha$ cellulose can be purchased from commercial suppliers, or, in small sizes, made on the NBS paper mill. This is not considered a serious problem in the final design and construction.

In the U.S. cases, the leak detectors are thermal conductivity cells (2). Briefly, these cells consist of fine spirals of Pt wire contained in a copper tube. Two of these are placed in open copper tubes within the case, and two others, placed in sealed copper tubes containing the same atmosphere as in the case at the time of filling, are outside the case. These four cells are arranged in a bridge. When current is passed through the bridge, the temperature of the wires, 
and hence the resistance of the legs of the bridge, is determined by the thermal conductivity of the ambient gas. As long as the ambient atmosphere (humidified helium) is the same for all the legs of the bridge, bridge balance results. If, however, a leak occurs in the case, the air leaking in, which has a much lower thermal conductivity than helium, will drastically change the thermal conductivity of the gas within the cases and bridge unbalance results.

It is difficult to conceive of a more reliable and fool-proof way of detecting leaks in the cases. The velocity of ultrasonic waves was investigated, and was the subject of a short report to Dr. Shahani (7). It was considered to be far more complicated and less reliable than the presently used thermal conductivity method. Indeed, this latter method, is essentially the same form as used in the U.S. cases is now used in commercial gas chromatographịc equipment. The sensors are essentially identical, although the material of the wires is different. All of these materials, including the bridge controls, are commercially available, and assembly into a leak detection system is considered routine.

7. Summary and Conclusions

a) A conceptual design for the enclosure in which the constitution of Puerto Rico is to be displayed is given. A more detailed design cannot be given without more information on the site than was available to us and without consideration of esthetic factors.

b) Condensation on the enclosure may be prevented by air conditioning the enclosure, but temperature control will be necessary to prevent condensation on the outside of the enclosure.

c) Ultraviolet light filters which absorb a portion of the visible spectrum should be used as protection for the documents of the Puerto Rican Constitution. This means a slightly yellow colored filter.

d) Designs for document cases that involve one, two, or four cases are presented. These designs may be used for hermetically sealed cases or for cases that are not so sealed. 
e) The method of construction of hermetically sealed cases presently used for the U.S. Constitution and Declaration of Independence is considered to be superior to other possible construction methods.

f) Hermetically sealed cases can be produced by coating the border of the glass of the cases with silver which is fired on during the glass tempering process. The method of construction of these cases is otherwise the same as for the U.S. cases. Tight solder joints that withstand the most severe anticipated service conditions can be made. However, it cannot be guaranteed that these cases will withstand air transport at an altitude of 10,000 feet.

In view of the above three options are open:

1) Ship the cases from the mainland USA to Puerto Rico by surface transport.

2) Do all the assembly and leak detection of the cases in the mainland USA, but do the final introduction of the case atmosphere in Puerto Rico. In this way, the cases could be shipped before final sealing, but all the critical soldercoating joints would have been made.

3) Do the full assembly in Puerto Rico.

g) It is very likely possible to produce a coating on the glass for the production of hermetically sealed cases by flame spraying, but the proper conditions were not found in this investigation.

h) The method of leak detection presently used in the U.S. cases is considered optimum from the standpoint of simplicity, reliability and sensitivity, provided helium is used as the atmosphere in the cases. 
30

References

1. C. Shahani, private communication.

2. "Preservation of the Declaration of Independence and the Constitution of the United States", NBS Circular 505, July 2, 1951.

3. M. Pirani and J. Parwood, "Principles of Vacuum Engineering", Reinhold Publishing Co., NY, 1961.

4. Local Climatological Data, San Juan, Puerto Rico, 1979 and 1980, National Oceanic and Atmospheric Administration, National Climate Center, Asheville, NC.

5. Standard Handbook for Mechanical Engineers, 8th Edition, McGraw Hill, NY 1978.

6. E. Shavers, private communication.

7. Letter, E. Passaglia to C. Shahani, September 30, 1982 (attached as Appendix A). 


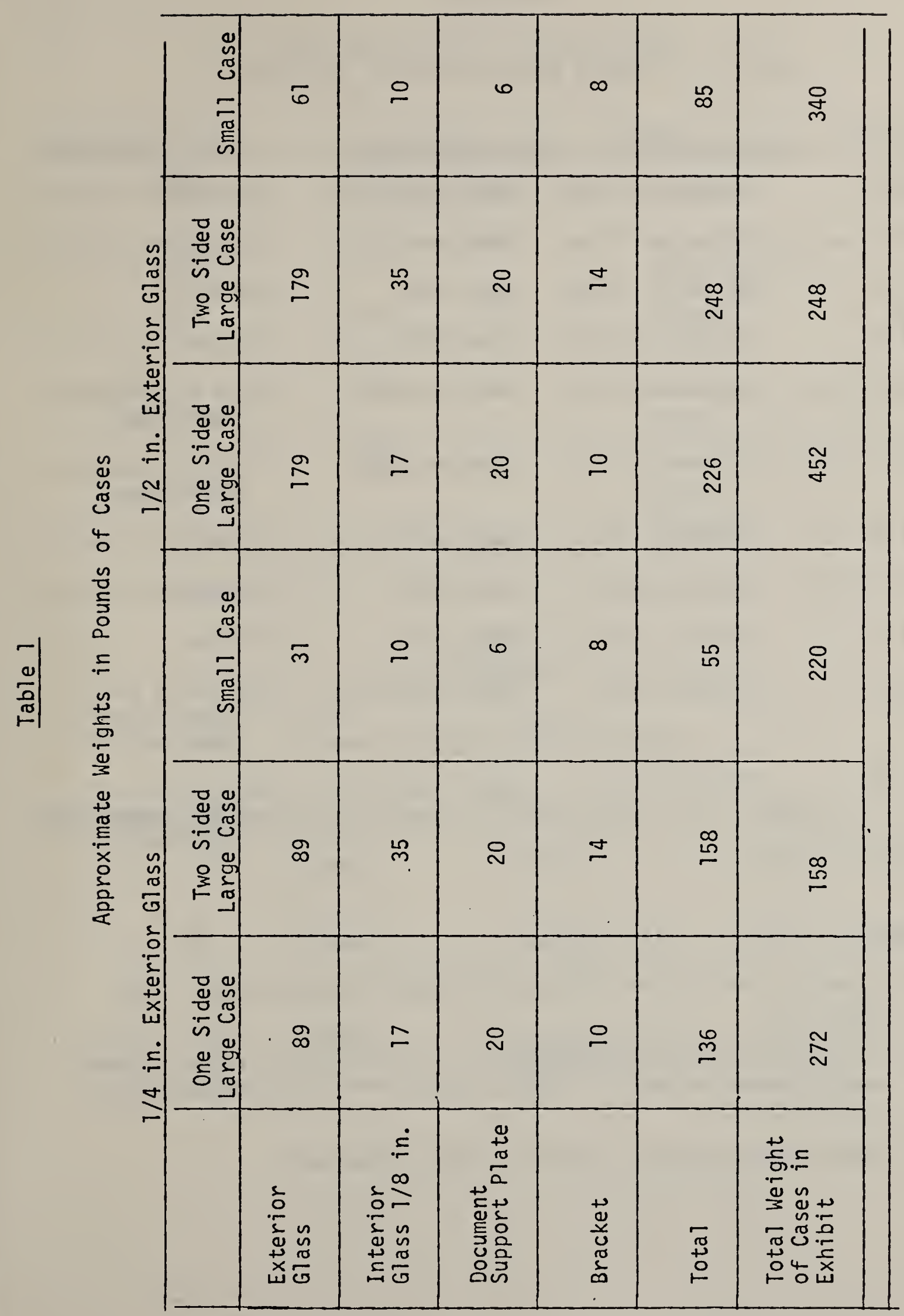




\section{Table 2}

Results of Coating During Tempering Operation

Size of Pane

$33 \times 40$

$33 \times 40$

$33 \times 40$

$33 \times 40$

$18 \times 24$

$18 \times 24$

$18 \times 24$

(c)

$18 \times 24$

(c)

$18 \times 24$

$18 \times 24$

(c)

$18 \times 24$
Coating

Ag paint, fresh Good coat

Ag paint, fresh Good coat

Ag paint, fresh Good coat

Ag paint, fresh Good coat

Ag paint, fresh Good coat

Ag paint, fresh Good coat

(b)

Good coat

Good coat

Good coat

Tape flaked off

Transfer tape

Transfer tape

(a)

(b)

Tape flaked off
Final Disposition

Assembled into case

Assembled into case

On hand

On hand

experiments

Used for soldering experiments

Assembled into case

Assembled into case

On hand

Pane used for flame spraying experiments
Pane used for flame spraying experiments

Notes

(a) A small crack appeared along outer edge after tempering. See note (b).

(b) Corner broke off during tempering. The PPG shop foreman informed us this occurred because edges of glass were not smoothed before tempering.

(c) These were prepared on March 22, 1983. See text. 
Table 3

Flame Spraying with Cu-Glass Frit

$18 \times 24$ panes

\begin{tabular}{|c|c|c|c|}
\hline Pane Number & Coating Appearance & Disposition & Result \\
\hline 1 & Reasonably Sound & Tinned & Coating came off \\
\hline 2 & Loose in places & $\begin{array}{l}\text { Used for tinning } \\
\text { experiments }\end{array}$ & \\
\hline 3 & Sound & Tinned & $\begin{array}{l}\text { One corner } \\
\text { lifted }\end{array}$ \\
\hline 4 & Sound & $\begin{array}{l}\text { Assembled into } \\
\text { case }\end{array}$ & Case leaked": \\
\hline 5 & Sound & $\begin{array}{l}\text { Assembled into } \\
\text { case }\end{array}$ & Case leaked \\
\hline 6 & Sound & On hand & \\
\hline
\end{tabular}

\section{$\underline{\text { Table } 4}$}

Flame Spraying with Pure Copper

\begin{tabular}{cccc} 
Pane Number & Coating Appearance & Disposition & Result \\
\hline 1 & Sound & Tinned & Corner Lifted \\
2 & Sound & $\begin{array}{c}\text { Assembled into } \\
\text { case }\end{array}$ & Case Leaked \\
3 & Sound & $\begin{array}{c}\text { Assembled into } \\
\text { case }\end{array}$ & Case Leaked
\end{tabular}


Table 5

Cases Constructed

$\begin{array}{lllll}\begin{array}{l}\text { Size } \\ 33 \times 39\end{array} & \begin{array}{l}\text { Coating } \\ \mathrm{Ag}\end{array} & \begin{array}{l}\text { Tinning Solder } \\ \text { Paste, active flux }\end{array} & \frac{\text { Result }}{\text { Case tight }} & \begin{array}{l}\text { Disposition } \\ \text { To enviromental } \\ \text { testing }\end{array} \\ 18 \times 24 & \mathrm{Ag} & \text { Wire, mild flux } & \text { Case tight } & \begin{array}{l}\text { To environmental } \\ \text { testing }\end{array} \\ 18 \times 24 & \text { Cu-Glass } & \text { Paste, active flux Case leaked } & \begin{array}{l}\text { Destroyed to } \\ \text { recover bracket }\end{array} \\ 18 \times 24 & \mathrm{Cu} & \text { Wire, mild flux } & \text { Case leaked } & \text { on hand }\end{array}$

Table 6

Correspondence Between Test Conditions and Ambient Conditions in Service Large Case

Test Temperature, ${ }^{\circ} \mathrm{F}$

50

130

50

130
Equivalent Site Conditions

${ }^{\mathrm{T}} \mathrm{F}$ in. $\mathrm{Hg}$

$T \quad P$

${ }^{\circ} \mathrm{F}$ in. $\mathrm{Hg}$

$\begin{array}{ll}62 & 30.5\end{array}$

94 over 31

$\begin{array}{ll}62 & 27\end{array}$

$94 \quad 28.1$

Small Case

$\begin{array}{llll}62 & 30.5 & 94 & \text { over } 31\end{array}$

$\begin{array}{llll}62 & 26.6 & 94 & 28.5\end{array}$ 


\section{Figure Captions}

Figure 1. A general view of the suggested display in plan (upper) and section (lower). A cylinder of polymethylmethacrylate is placed in the recess of the existing pedestal. The document cases are placed within this cylinder. Shown here are the four double-sided small cases. Scale: $l=15$.

Figure 2. View of the large display case containing fifteen documents. The edges of the documents are shown as dotted lines on the center three documents. The smaller rectangles indicate the viewing holes in the mat. Scale $7=4.38$.

Figure 3. Same as Figure 2, but for the small cases. The $x^{\prime} s$ represent the lettering on the documents. Scale: $1=2.4$.

Figure 4. Exploded view showing the manner in which the documents are supported to prevent them from slipping. The documents are placed in recess in the document support plate and are overlayed by this mat which is held against them as shown in Figure 4.

Figure 5. A cross section of the double-sided document case showing the method of supporting the documents and of sealing the case.

Figure 6. The temperature-time schedule followed for the environmental testing. 


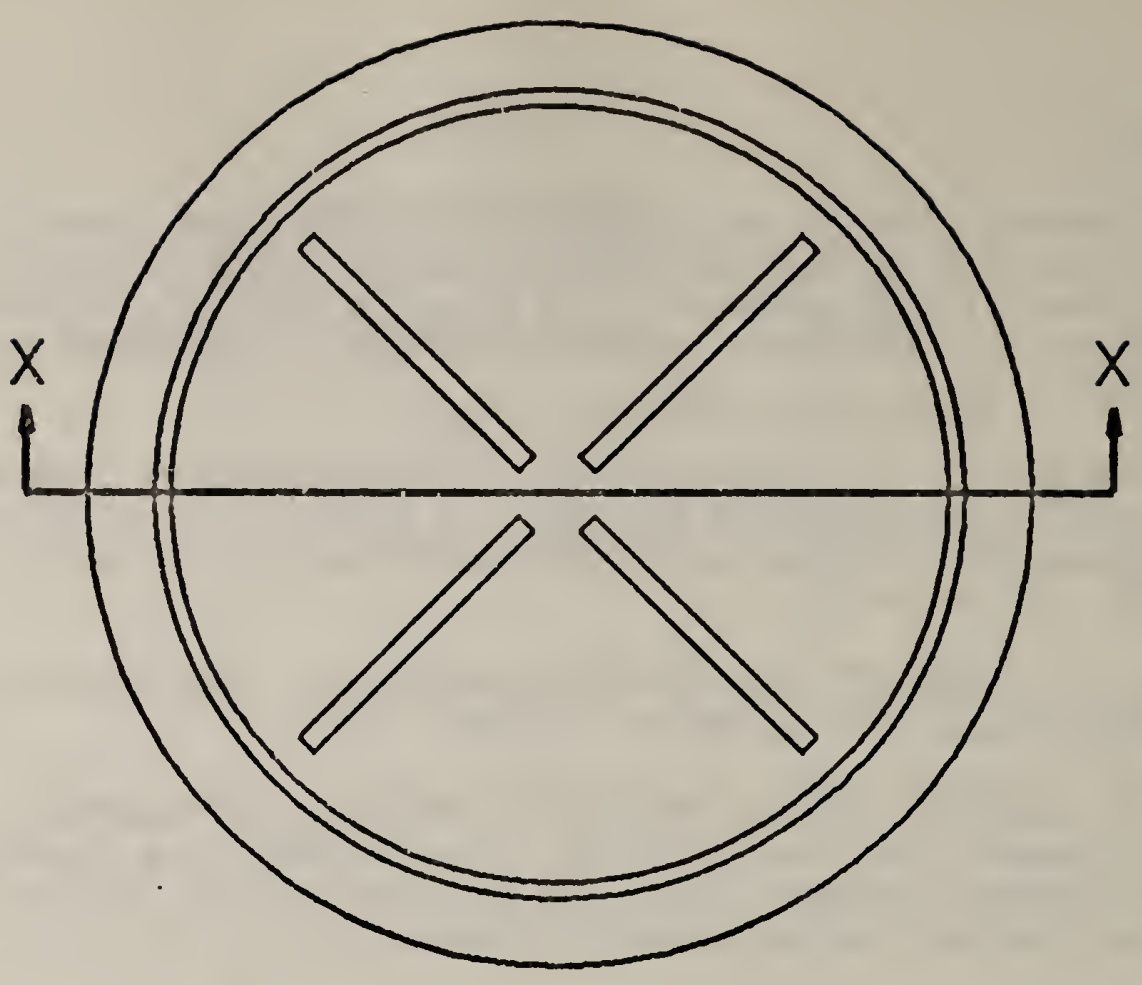

Figure 1

SEC . $X-X$

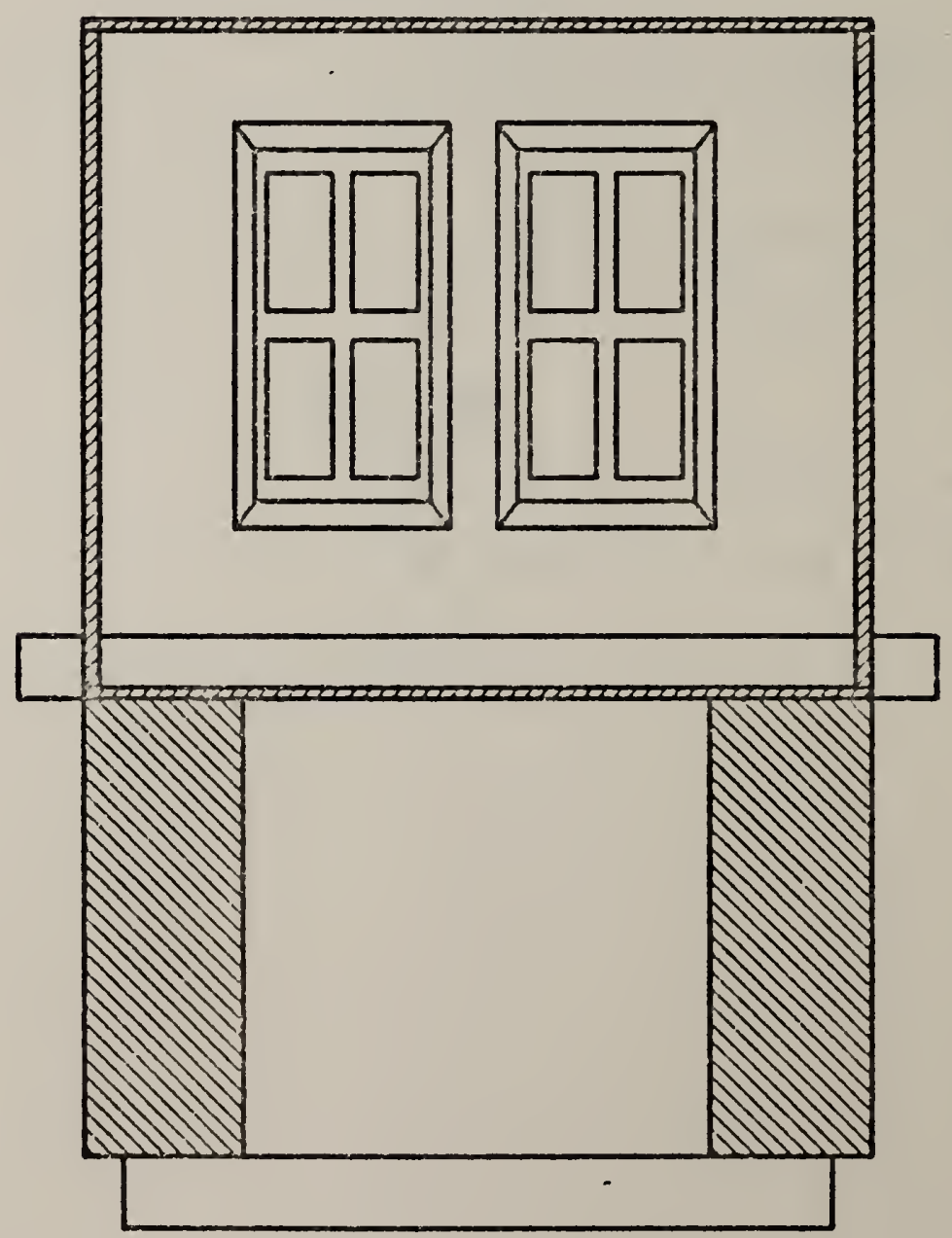


Figure 2
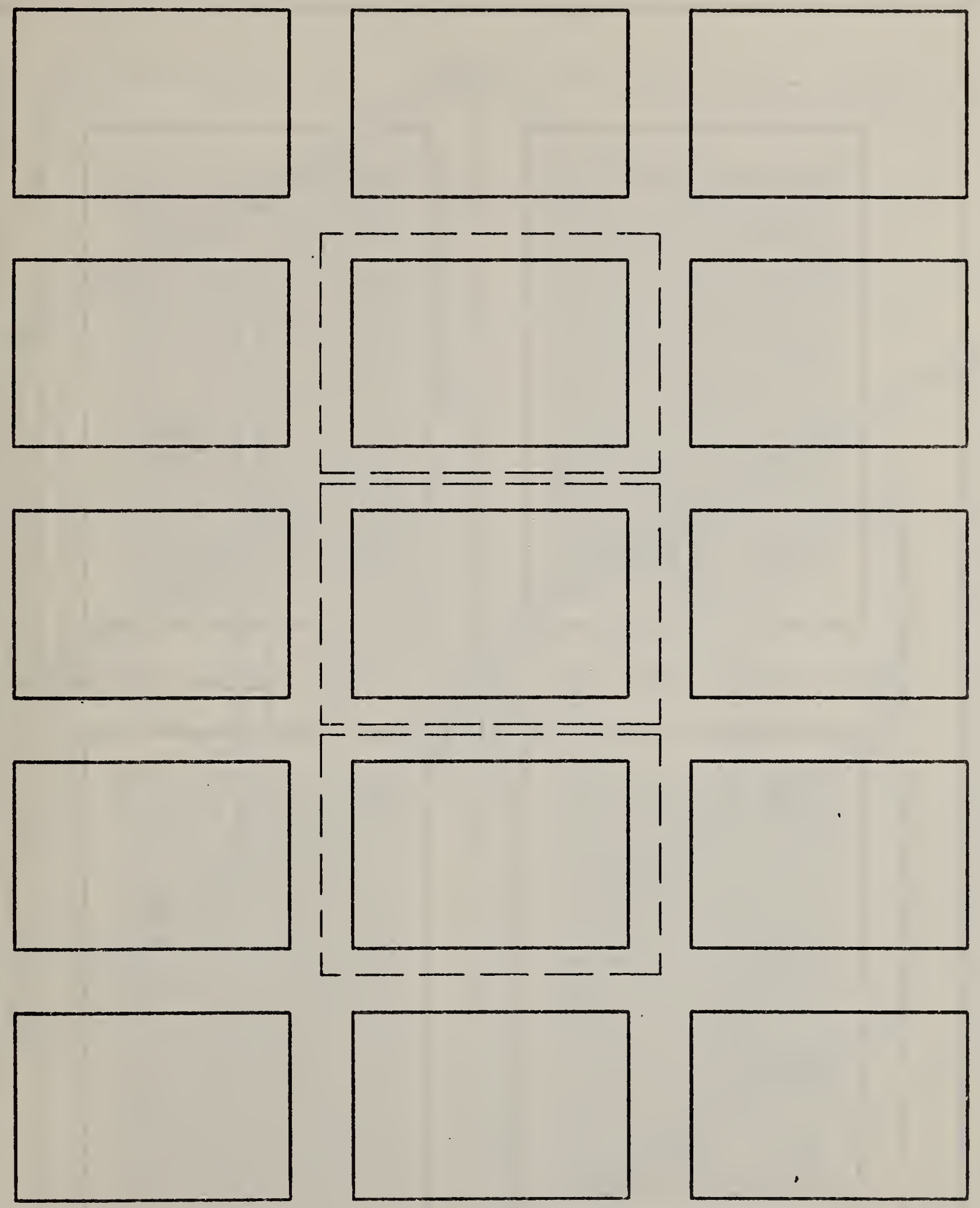
Figure 3

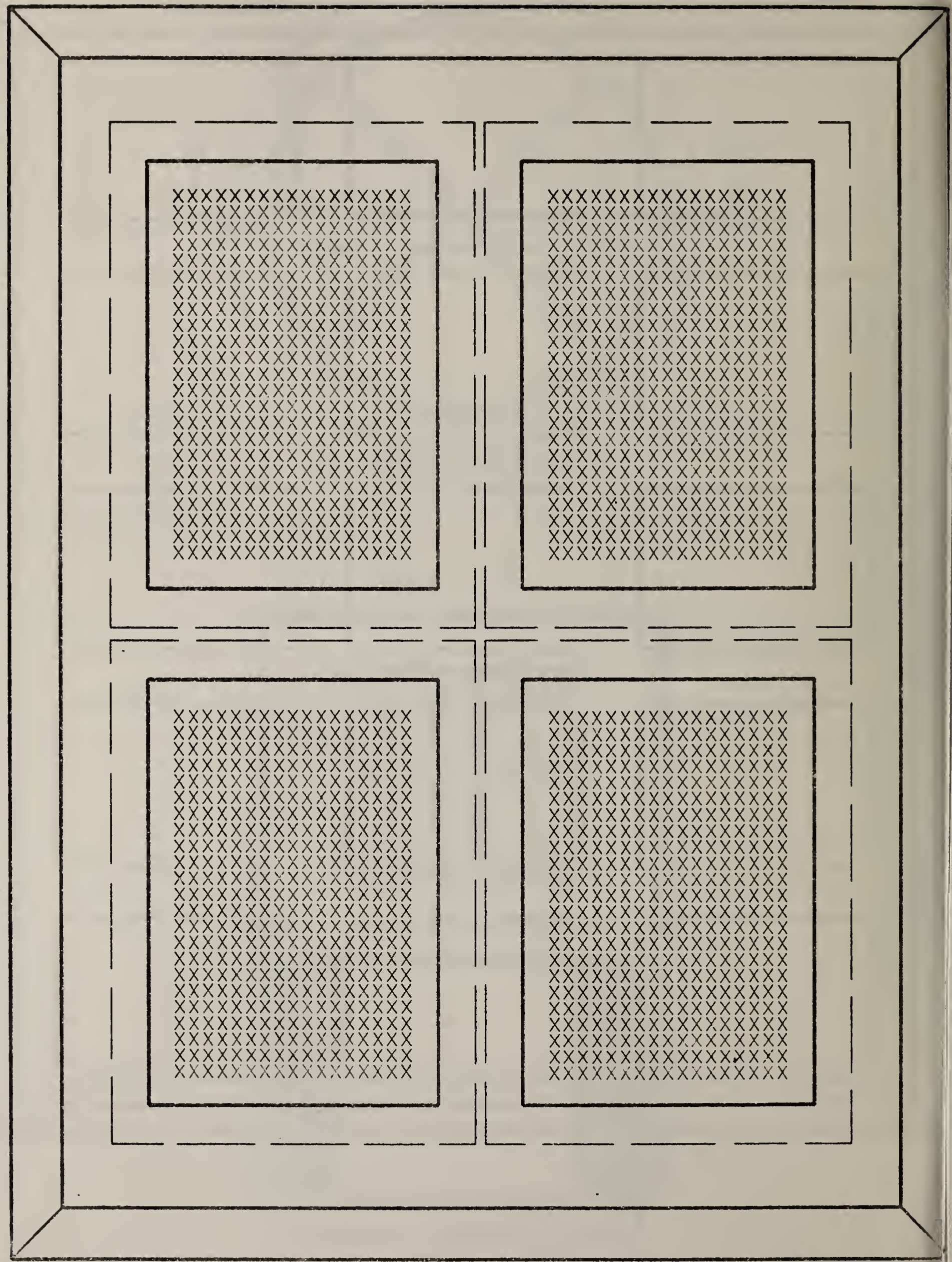




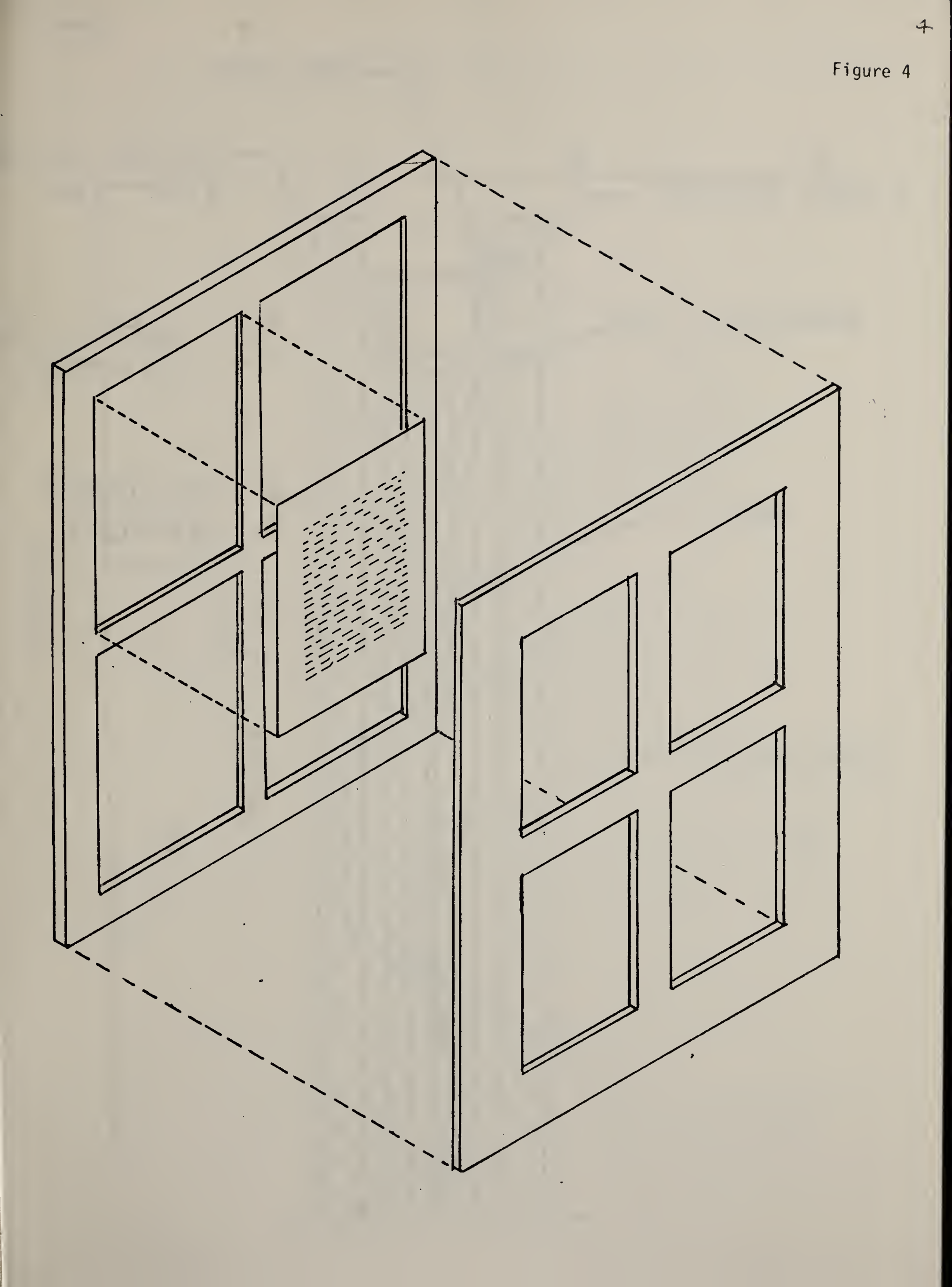


Figure 5

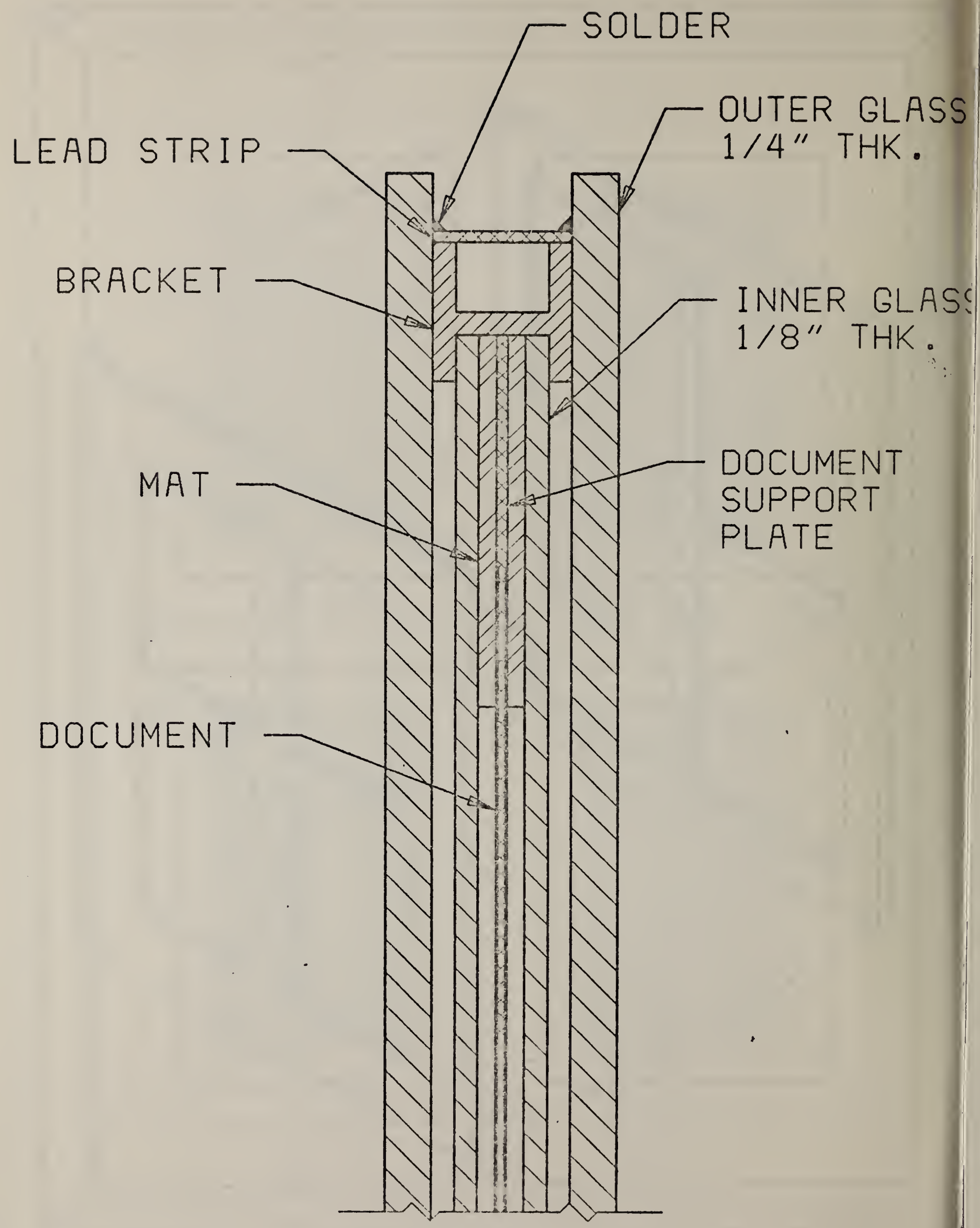




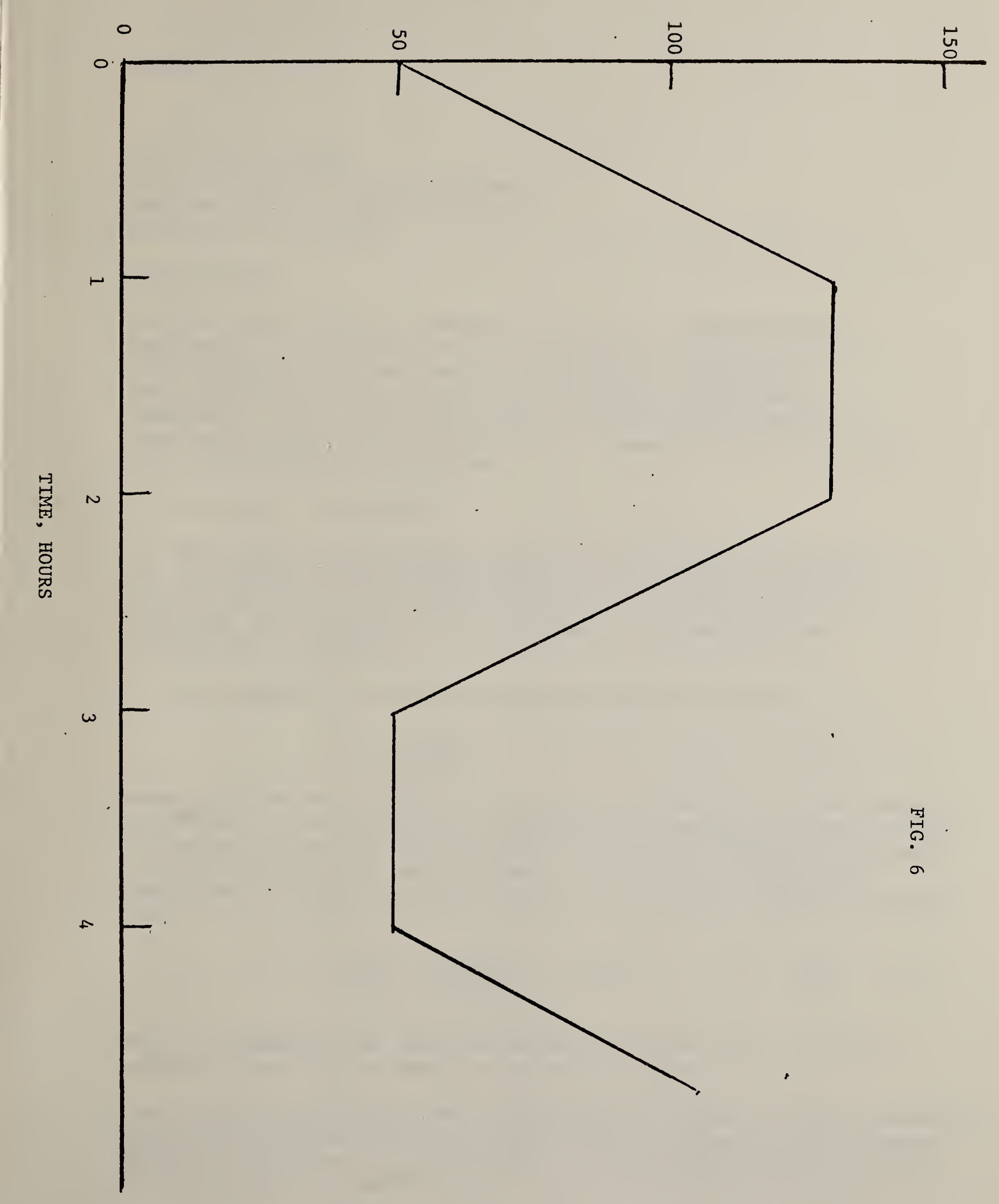




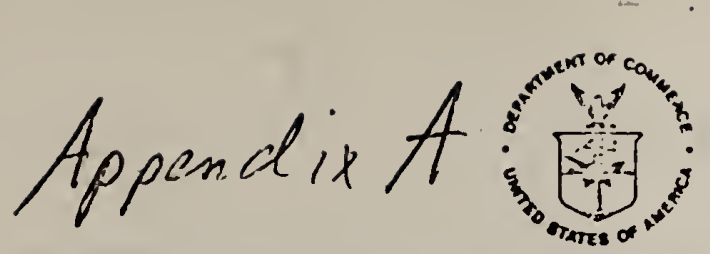

UNITED STATES DEPARTMENT OF COMMERCE

National Bureau of Standards

Washington, D.C. 20234

September 10,1982

Dr. Chandru Shahani

Chief, Document Preservation Branch

National Archives and Records Service

Washington, D.C. 20408

Dear Chandru:

In this letter I want to summarize for you the investigations I have made on the possibility of using ultrasonic measurements for the determination of air content in the cases in which the Constitution and Declaration of Independence are contained. Subsequent to our last conversation, and after some travel and vacation, I talked to $\mathrm{Dr}$. Singh, as you suggested. His information to me is included in this letter.

1) Principle of the Method.

The velocity of sound in helium at $0^{\circ} \mathrm{C}$ is $970 \mathrm{~m} / \mathrm{sec}$, while for air it is $331 \mathrm{~m} / \mathrm{sec}$ ( 1 ). Hence, the velocity is quite different for the two gases, and, by measuring it, it should be possible to determine the percentage of air in helium. This may be shown analytically as follows.

The velocity of sound in an ideal gas is given by (1),

$$
v=\frac{\sqrt{R T \gamma}}{M}
$$

where $R$ is the gas constant, $T$ the absolute temperature, $M$ the molecular weight and $\gamma$ the ratio of the specific heat at constant pressure to that at constant volume. We consider both helium and air to be ideal gases, which is sufficient for our purposes. For helium, $Y=4$ and $\gamma=1.67$ (monotomic) while for air, $M=29$ and $\gamma=1.4$ (diatomic). Using Eq. (1) we get.

$$
\frac{v_{\text {He }}}{v_{\text {air }}}=\frac{\sqrt{29 \times 1.4}}{.4 \times 1.6}=2.52
$$

which is somewhat lower than the handbook value of 2.92 , but close enough to determine the requirements on the method.

Now, we wish to calculate the change in sound velocity for small admixtures of air into helium. When air is admitted into helium, both the average molecular weight and $\gamma$ will change. The average molecular weight $\bar{M}$ of a mixture of air and helium is

$$
\bar{M}=\mathrm{XM}_{\mathrm{A}}+(1-\mathrm{X}) \mathrm{ML}_{\mathrm{He}}{ }^{-}
$$

where $X$ is the mole fraction of air. The expression for $\gamma$ is more 
complicated. The quantity $\gamma$ is the ratio of the specific heat at constant pressure $\left(C_{p}\right)$ to that at constant volume (Cv). Since for ideal gases the specific heats are additive we get for the average $\gamma$ for the mixture, $\bar{\gamma}$,

$$
\bar{\gamma}=\frac{c_{p}^{A} X+c_{p}^{H e}(1-X)}{c_{v}^{A} X+\dot{C}_{v}^{H e}(1-X)}
$$

Now we wish to calculate the fractional change in sound velocity for a given change in concentration, i.e., X. For small changes, from Eq. 1 we get

$$
\frac{1}{v} \frac{d v}{d x}=-\frac{1}{2} \frac{1}{\bar{M}} \frac{d \bar{y}}{d x}+\frac{1}{2} \frac{1}{\bar{\gamma}} \frac{d \bar{y}}{d x}
$$

Now, from Eq. (3), we get

$$
\frac{d \bar{M}}{d x}=M_{A}-M_{H e}
$$

From Eq. 4 and the known values of specific heats for monatomic and diatomic ideal gases we get this simple expression for $\mathrm{d} \bar{\gamma} / \mathrm{dx}$

$$
\frac{d \bar{\gamma}}{d x}=-\frac{4}{[3+2 x]^{2}}
$$

Finally we get for the fractional change in velocity

$$
\frac{d v}{v}=-\frac{1}{2}\left[\frac{M_{A}-M_{H e}}{\bar{M}}+\frac{4}{\bar{\gamma}(3+2 x)^{2}}\right] d x
$$

To determine the sensitivity of the ultrasonic method, we now calculate the fractional change in velocity when $1 \%$ air is admixed into pure helium, both considered to be ideai gases. In this case we take

$$
\begin{aligned}
& M_{A}=29 \\
& M_{H e}=\bar{M}=\cdot 4 \\
& \bar{\gamma}=\gamma_{H e}=1.66 \\
& d x=0.01
\end{aligned}
$$

The arithmetic gives $\mathrm{dv} / \mathrm{v}=-0.033$. The final result is that when $1 \%$ air is mixed with pure helium, the velocity of sound decreases approximately $3.3 \%$. With this figure we can now proceed to calculate the requirements of our system. 


\section{2) Application to Cases.}

For this application we need to calculate two things:

1. The total transit time in the gas space in the case. This and the previous calculation will give us the required time measurement sensitivity. With the knowledge of the thickness of the gas space, this gives the sound velocity.

2. The ratio of the magnitude of the reflected signal to the transmitted signal. This will tell us the requirements on the signal sensitivity of the system.

\section{1) Transit Time.}

The attached figure gives a sketch of the situation considered. The purpose of the glass stand off will be discussed later. The dimension of the gas space is about $0.1^{\prime \prime}(0.25 \mathrm{~cm})$. The total transit time $\Delta t$ in the gas is thus

$$
\Delta t=\frac{2 \times 0.25}{v}
$$

For pure helium we get $\Delta t=5.2 \mu \mathrm{sec}$. If $1 \%$ of air is mixed with the helium, we have seen that the velocity is decreased by $3.3 \%$. Hence the change in transit time is $0.17 \mu \mathrm{sec}$. With this capability in time measurement we will just be able to detect $1 \%$ air. To make certain of detection, we ought to be able to have a capability about ten times this, or $0.017 \mu \mathrm{sec}$. The meaning of this will be discussed later.

We note here that there will be three main returs signals from a transmitted pulse: one from the first glass - gas interface; one arriving, as we have just seen, $5.2 \mu \mathrm{sec}$. later from the gas-second glass interface; and one arriving about $1.9 \mathrm{\mu} \mathrm{sec.} \mathrm{after} \mathrm{that} \mathrm{one} \mathrm{from} \mathrm{the} \mathrm{glass-}$ document interface. To give sufficient time after the initiation of a pulse to receive a signal without interference with the transmitted pulse, a stand of $\mathrm{f}$ is necessary, as shown in the figure. This was suggested by Dr. Singh. For a two inch stand-off the total time between the initiation of a pulse and the first return echo from the first glass - gas interface is $22.9 \mu \mathrm{sec}$, using $5000 \mathrm{~m} / \mathrm{sec}$ for the velocity of sound in glass (1). This is the maximum pulse length that could be used. Actually, the pulse would be quite a bit shorter. Without the stand off, the time between pulse initiation and the return of the first echo is $2.5 \mu \mathrm{sec}$.

\section{2) The Anplitude of the Return Echo.}

In order to measure the velocity of scund in the gas space ve need to measure the transit time (and, of course, know the thickness of the gas space, as will be discussed iater). This means reasuring the time from the first return echo (from the first glass - gas interface) to the second return ccho (from the gas-second glass interface). The second return echo will be very weak. This can be seen as follows: The reflection cocfficient, $R$, and the transmission cocfficient $T$, for ultrasonic waves at a boundary 
between medium 1 and medium 2 are given by (1),

$$
R_{12}=\frac{\rho_{1} v_{1}-\rho_{2} v_{2}}{\rho_{1} v_{1}+\rho_{2} v_{2}}
$$

and

$$
T_{12}=\frac{2 \rho_{2} v_{2}}{\rho_{1} v_{1}+\rho_{2} v_{2}}
$$

where $\rho$ and $v$ are the density and velocity, respectively. It is clear from the diagram that the ratio of the amplitude of the pulse from the gas-second glass interface to that incident on the first glass - gas interface (essentially the amplitude of the transmitted wave) is given by

$$
\frac{A_{r}}{A_{i}}=T_{g f} R_{f g} T_{f g}
$$

where

$$
\begin{aligned}
& A_{r}=\text { Amplitude of return wave } \\
& A_{i}=\text { Amplitude incident wave } \\
& T_{g f}=\text { Transmission coefficient from glass to gas (fluid) } \\
& R_{f g}=\text { Reflection coefficient at gas - glass interface } \\
& T_{f g}=\text { Transmission coefficient from gas to glass }
\end{aligned}
$$

Usịng Eqs. (11) and (12) we get,

$$
\frac{A_{r}}{A_{i}}=\frac{4 \rho_{f} v_{f} \rho_{g} v_{g}\left(\rho_{f} v_{f}-\rho_{g} v_{g}\right)}{\left(\rho_{f} v_{f}+\rho_{g} v_{g}\right)^{3}}
$$

Now, the density and velocity for helium are greatly different than those for glass. For helium, $\rho_{f_{f}}=17.32 \mathrm{gm} / \mathrm{cm}^{2} \mathrm{sec}$, while for glass, $\rho_{\mathrm{g} g}^{\mathrm{v}}=1.2 \times 10^{6} \mathrm{gm} / \mathrm{cm}^{2} \mathrm{sec}$. . Hence, Eq. 13 becomes

$$
\frac{A_{r}}{A_{i}} \equiv \frac{4 v_{f}{ }^{\circ}}{v_{g}{ }^{\circ}}=5.5 \times 10^{-5}
$$

This means that the amplitude of the signal from the gas - second glass interface is only $5.5 \times 10^{-5}$ that from the first glass - gas interface.

3) Discussion and Summary.

What we have learned from the above may be summarized as follows

a) Addition of $1 \%$ air to helium decreases the velocity of sound by $3 \%$.

b) To be able reliably to detect $1 \%$ air. in helium in the document cases requires an ability to measure a time interval of approximately flve microseconds with a precision of about 0.02 " sec. 
c) The return signal has an amplitude of about $5.5 \times 10^{-5}$ times the amplitude of the transmitted signal.

d) The transducer needs a glass standoff of about two inches to permit a reasonable pulse length.

With respect to the ability to carry out items (b) and (c) above, I have had some preliminary discussions with our ultrasonics experts with -these results. First, the ability to measure time interval to $0.02 \mu \mathrm{sec}$. is within the state of the commercial art, but would require a high quality time interval meter. Second, with respect to the amplitude of the return signal, gains of $80 \mathrm{~dB}\left(\mathrm{x} 10^{4}\right)$ are routinely used, and gains of $100 \mathrm{~dB}\left(\times 10^{5}\right)$ are not uncommon. Thus, it seems possible to carry out the measurements to detect the entrance of $1 \%$ air in helium, all other things being constant.

Other aspects of the system are, however, not so clear. These will depend upon whether the device is to be used as a monitcring system, or whether the device is to be used to measure the velocity of sound in the present cases to see if air has leaked into them. Let me discuss the se two.

\section{1) Monitoring System.}

For this case, only a relative measurement of transit time is necessary. The system is assembled with the standoff rod anc transducer coupled to the case. The transit time is monitored periodically, and all should work well provided the coupling of the transducer to the rod and the rod to the case is not disturbed. This is a critical part of the whole design, and for the system to work well, this coupling (and the transducer) should be stable over a period of many years, and with handling. The matter of coupling is as much a question of art as of science. Since the absolute value of the amplitude of the return signal is not important and only the time interval between echoes is, the requirements are somewhat nitigated, but development work would be necessary to determine the effect of the coupling on performance.

\section{2) Measuring in the Present Cases.}

This requires an absolute measurement of sound velocity in the present cases. First, this would require an accurate krowledge of the thickness of the gas space, which we do not have. A reliable system would have to be built, including an investigation of the effects of the coupling problem. If we were to assume that we know the thickness of the gas space to $\pm 10 \%$ (this may be totally unwarrented), and we were to have solved all the system problems, then it might be possible to detect the presence of $10 \%$ air in the helium. It is felt, however, that this would require a significant development effort. 


\section{3) Summary}

With the sound velocity measurement technique it is in principle possible to detect the leakage of air into cases like those containing the Constitution and the Declaration of Independence. The requirements on the technique are much more stringent for the detection of air in the present cases than they are for monitoring and a significant development effort would be required to develope a reliable system. However, even In the monitoring case, considerable development work would be necessary to assure that a reliable system with long term stability (30 years or so) has been developed. It is felt that it will be extrencly difficult to develope a system that is as reliable, and certainly as inexpensive, as the present system based on thermal conductivity.

I believe this covers most of the issues that are likely to arise in the ultrasonic method of leak detection. I should, however, point out that what is expressed are my own views arrived at by my own efforts and after consultation with some of the NES staff. This does not constitute an official report of NBS. If you have any questions do not hesitate to call.

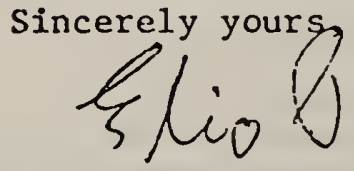

Elio Passaglia

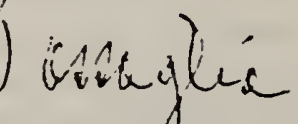

Structure and Propertiés Group

Polymer Science and Standards Division

\section{Reference}

(1) American Institute of Physics Handbook, McGraw-Hill, N.Y., 1957 Chapter 3.

bcc: Eby

Fanconi

L. Smith 


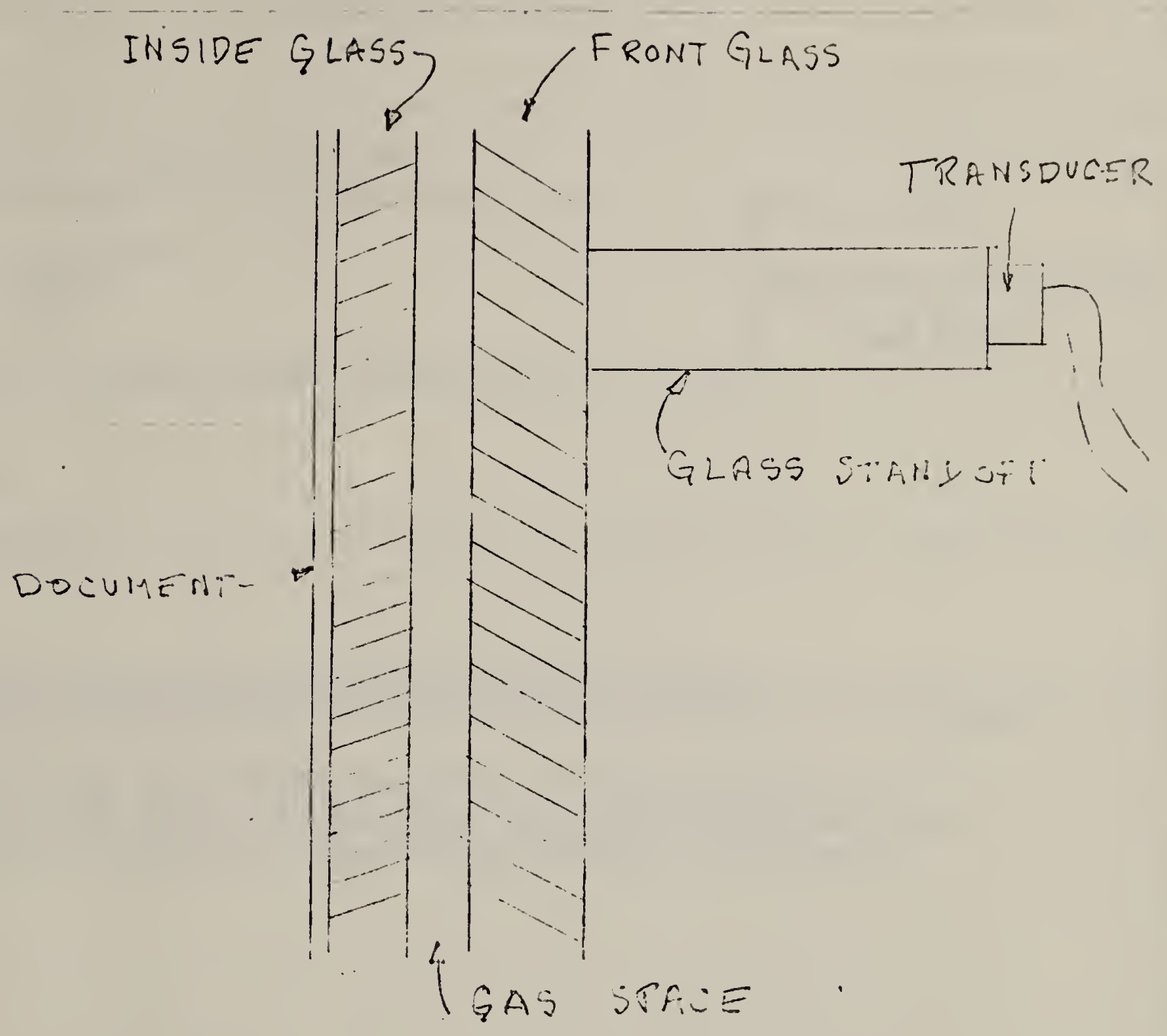



NBS.114A (REV. 2-BC)

U.S. DEPT. OF COMM.

BIBLIOGRAPHIC DATA

SHEET (See in structions)

4. TITLE AND SUBTITLE

5. $A \cup T H O R(S)$

E. Passaglia, D. Brown, B. Dickens

6. PERFORMING ORGANIZATION (If joint or other than NBS. see in structions)

7. ContracuGrant No.

NATIONAL BUREAU OF STANDARDS

DEPARTHENT OF COMMERCE

WASHINGTON, D.C. 20234

8. Type of Report \& Period Covered

Final Report

9. SPONSORING ORGANIZATION NAME AND COMPLETE ADDRESS (Street, City, Stote, ZIP)

10. SUPPLEMENTARY NOTES

[] Document describes a computer program; SF-185. FIPS Software Summary, is attached.

11. ABSTRACT (A 200-word or less factual summary of most significant information. If document includes a significant bibliography or literature survey. mention it here)

A general design for a display enclosure for the Constitution of

Puerto Rico, and designs and methods of construction of hermetically

sealed cases to contain the constitution documents are presented.

12. KEY WORDS (Six io twelve entries; alphabetical order; capitalize only proper names; and separate key words ty semicolons)

Constitution of Puerto Rico; documents; construction.

13. AVAILABILITY

$\bar{X} \bar{X}$ Unlimited

[ For Official Distribution. Do Not Release to NTIS

[X] Order From Superintendent of Documents, U.S. Government Printing Office, Washington, D.C. 20402 .

Order Fiom National Technical Information Service (NTIS), Springfield, VA. 22161
14. NO. OF

PRINTED PAGES

50

15. Price

$\$ 8.50$ 


